\title{
Biodiversitas Burung pada Perkebunan Kelapa di Kabupaten Minahasa Utara, Provinsi Sulawesi Utara \\ (Bird Biodiversity in Coconut Plantation in North Minahasa Distric, North Sulawesi Province)
}

\author{
Jayens Alotia ${ }^{1)^{*}}$, Saroyo ${ }^{1)}$, Sendy Rondonuwu ${ }^{1)}$ \\ ${ }^{1)}$ Program Studi Biologi, FMIPA Universitas Sam Ratulangi, Manado 95115 \\ *Email korespondensi: jayensalotia70@gmail.com
}

Diterima 1 Februari 2019, diterima untuk dipublikasi 28 Februari 2019

\begin{abstract}
Abstrak
Burung memerlukan tempat atau ruang yang digunakan untuk mencari makan, minum, berlindung, bermain, dan tempat berkembang biak. Penelitian ini bertujuan untuk menganalisis biodiversitas burung pada habitat perkebunan kelapa di Kabupaten Minahasa Utara. Pengambilan data dilaksanakan dari bulan Desember 2017 sampai dengan bulan Maret 2018 di perkebunan kelapa di Desa Maumbi, Desa Tatelu dan Desa Pinili Kabupaten Minahasa Utara, Provinsi Sulawesi Utara. Pengambilan data dilakukan dengan menggunakan metode survei. Teknik penentuan petak contoh menggunakan metode purposive sampling yaitu teknik penentuan sampel dengan pertimbangan tertentu. Petak contoh ditentukan sebanyak 3 transek berbentuk garis transek (line transect) dengan panjang masingmasing transek $2000 \mathrm{~m}$ dan lebar $20 \mathrm{~m}$ dengan pengambilan data sebanyak 5 kali. Berdasarkan penelitian diperoleh hasil sebanyak 23 jenis burung dengan indeks biodiversitas sebesar 2.76, dari 23 jenis burung tersebut diketahui jumlah jenis burung yang dianggap kurang mengkhawatirkan (LC) terdapat 21 jenis burung, sedangkan status rentan (VU) terdapat 1 jenis yaitu Penelopides exarhatus dan status hampir punah (NT) terdapat satu jenis yaitu Accipiter nanus.

Kata kunci: biodiversitas, burung, perkebunan kelapa, Kabupaten Minahasa Utara.
\end{abstract}

\begin{abstract}
Birds buy places or spaces that are used to find food, drink, shelter, play, and breed. This study aims to analyze biodiversity in coconut plantation habitat in North Minahasa Regency. Data collection was carried out from December 2017 to March 2018 in coconut plantations, North Minahasa Regency, North Sulawesi Province in Maumbi Village, Tatelu Village, Pinili Village. Data retrieval is done using the survey method. The sampling technique uses purposive sampling method which is a sample selection technique with certain considerations. Sample plots are determined by 3 transects, forming line transects (line transects) with the length of each transect of $2000 \mathrm{~m}$ and width of $20 \mathrm{~m}$ by taking data 5 times. Based on research conducted in plantation habitats, North Minahasa Regency obtained research on species of birds on plantations in North Minahasa Regency, North Sulawesi Province, which consisted of 23 species of birds with a biodiversity index of 2.76, of 23 species of birds there are according to the type of bird that is considered less alarming (LC) there are 21 species of birds, while the vulnerable status (VU) there is 1 type, Penelopides exarhatus and the status is almost extinct (NT) there is 1 type, Accipiter nanus.

Keywords: biodiversity, birds, coconut plantations, North Minahasa Regency.
\end{abstract}




\section{PENDAHULUAN}

Indonesia merupakan negara dengan kekayaan hayati yang sangat tinggi, sehingga dimasukkan dalam negara megabiodiversitas. $\mathrm{Hal}$ ini ditunjukkan salah satunya dengan kekayaan spesies burung. Indonesia memiliki 1.598 jenis burung, dengan 381 jenis diantaranya merupakan jenis endemik (Sukmantoro et al. 2007). Salah satu wilayah di Indonesia yang memiliki biodiversitas burung yang tinggi ialah Pulau Sulawesi dengan 380 jenis (Andrew 1992). Dari jumlah tersebut, 96 jenis diantaranya bersifat endemik dan 60 jenis dengan sebaran terbatas.

Sulawesi dengan luas 187.882 $\mathrm{km}^{2}$ merupakan pulau terbesar dan terpenting di daerah biogeografi Wallacea. Daerah biogeografi Wallacea meliputi Pulau Sulawesi dan pulaupulau lain yang berada di antara Garis Wallace di sebelah barat dan Garis Lydekker di sebelah Timur. Ditinjau dari sejarah geologinya, Pulau Sulawesi sangat menarik karena diduga pada masa lampau, pulau ini tidak pernah bersatu dengan daratan manapun (Coates dan Bishop 2000). Keadaan terisolasi dalam kurun waktu yang lama memungkinkan terjadinya evolusi pada berbagai spesies, sehingga pulau Sulawesi mempunyai tingkat endemisitas yang tinggi (Coates dan Bishop 2000).

Burung (aves) merupakan salah satu kelas hewan bertulang belakang dan berdarah panas, berkembang biak dengan bertelur. Tubuhnya tertutup bulu dan memiliki bermacam-macam adaptasi untuk terbang (Alikodra 2002).

Cara hidup burung sebagian besar ditentukan oleh faktor habitat. Beberapa jenis hidup pada beberapa tipe habitat, sedangkan yang lain hidup pada satu tipe habitat saja. Habitat sebagai tempat tinggal suatu organisme untuk melaksanakan kehidupannya seperti mencari makan, minum, berlindung, bermain, dan berkembang biak.

Menurut Alikodra (1993), kondisi kualitas habitat akan menentukan komposisi, penyebaran, dan produktivitas satwa liar termasuk burung. Burung hidup hampir di seluruh tipe habitat dan pada berbagai ketinggian tempat seperti pulau-pulau, perkebunan kelapa, hutan mangrove, hutan rawa, rawa payau, danau, persawahan, padang rumput, semak belukar, dan padang savana (Coates dan Bishop 2000).

Tipe habitat burung sangat berhubungan dengan kehidupan dan aktivitas hariannya seperti tempat untuk beristirahat, bertengger, kawin, makan, berlindung, dan bersarang (Syafrudin 2011). Habitat mempunyai peran penting untuk mendukung kehidupan satwa liar (Alikodra 1993). Salah satu tipe habitat di Pulau Sulawesi yang potensi untuk kehidupan burung ialah perkebunan kelapa.

Pulau Sulawesi memiliki luas perkebunan kelapa $6.8 \%$ dari total perkebunan kelapa di Indonesia (86.950 Ha) pada tahun 2016. Provinsi di Sulawesi yang memilik perkebunan kelapa yang luas ialah Sulawesi Utara. Di Sulawesi Utara, perkebunan kelapa memiliki karakteristik seperti hutan sekunder

Sulawesi Utara memiliki tingkat produktivitas tanaman kelapa yang tinggi. Rata-rata areal lokasi penelitian di perkebunan kelapa Kabupaten Minahasa Utara memiliki tipe habitat serupa hutan sekunder yang mampu menunjang kehidupan jenis burung.

Tanaman kelapa tumbuh di daerah tropis, dapat dijumpai mulai dari dataran rendah hingga dataran tinggi. Ancaman utama terhadap kelangsungan hidup burung, termasuk di perkebunan kelapa adalah kerusakan habitat dan pemburuan liar. Jika hal tersebut terus berlangsung maka akan terjadi kepunahan lokal untuk beberapa jenis burung (Coates dan Bishop 2000). 
Beberapa penelitian tentang burung yang sudah pernah dilakukan di kawasan perkebunan, misalnya oleh Aratrakhorn et al., (2006) pada perkebunan kelapa sawit di Thailand. Selanjutnya Azman et al. (2011) melaksanakan penelitian tentang biodiversitas burung dan jenis makanannnya di hutan sekunder, perkebunan kelapa sawit, dan ladang padi di kawasan riparian Lembangan Sungai Kerian Perak, Malaysia. Jenis burung dan penyebarannya di perkebunan kelapa di Kabupaten Minahasa Utara belum diketahui secara pasti. Oleh karena itu, perlu dilakukan penelitian tentang biodiversitas burung pada habitat perkebunan kelapa di salah satu wilayah Sulawesi Utara, yaitu Kabupaten Minahasa Utara. Penelitian ini bertujuan untuk menganalisis biodiversitas burung pada habitat perkebunan kelapa di Kabupaten Minahasa Utara.

\section{METODE}

Penelitian ini dilaksakanakan dari bulan Desember 2017 sampai dengan bulan Maret 2018 di perkebunan kelapa, Kabupaten Minahasa Utara Provinsi Sulawesi Utara di Desa Maumbi, Desa Tatelu, Desa Pinili (Gambar 1).

Pengambilan data dilakukan dengan menggunakan metode survei (Bibby et al. 2000). Teknik penentuan petak contoh menggunakan metode purposive sampling yaitu teknik penentuan sampel dengan pertimbangan tertentu (Michael 1995). Petak contoh ditentukan sebanyak 3 transek berbentuk garis transek (line transect) dengan panjang masingmasing transek $2000 \mathrm{~m}$ dan lebar $20 \mathrm{~m}$ dengan pengambilan data sebanyak 5 kali.

Data yang diambil meliputi jenis dan jumlah burung setiap jenis pada lokasi pengamatan. Pengambilan data dilakukan mulai pukul 06.00-10.00 Wita dengan kecepatan pengamatan 1 $\mathrm{km} / \mathrm{jam}$. Pengamatan pada setiap petak contoh dilakukan selama 5 kali. Semua burung yang teramati di dalam petak contoh diidentifikasi berdasarkan tanda-tanda khusus pada burung yang diamati. Tanda-tanda yang utama seperti bentuk paruh, ekor, kaki dan warna bulu. Tingkah laku dapat juga dijadikan dasar untuk mengenali suatu jenis burung (Iskandar 1989).

\section{HASIL DAN PEMBAHASAN Biodiversitas Burung}

Kabupaten Minahasa Utara merupakan daerah di Provinsi Sulawesi sebagai tempat berlindung, bersarang, mencari makan, dan bereproduksi bagi jenis-jenis burung yang ada. Luas area perkebunan kelapa di Kabupaten Minahasa Utara sebesar 250.000 hektar pada tahun 2016 (BPS Kabupaten Minahasa Utara 2008).

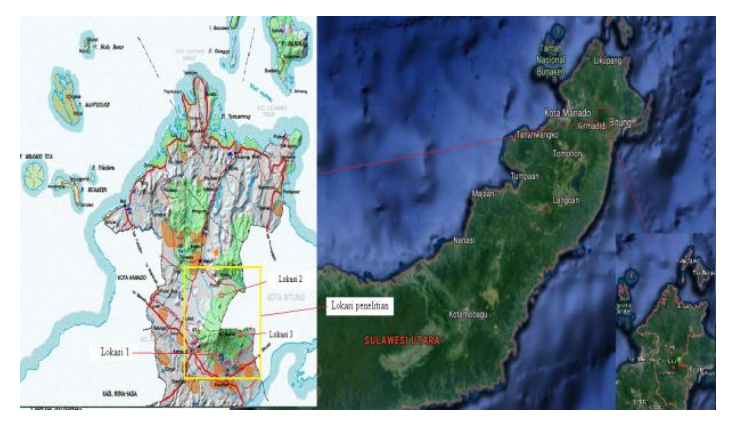

Gambar 1. Peta lokasi penelitian perkebunan kelapa Kabupaten Minahasa Utara.

Jumlah bangsa burung yang ditemukan selama penelitian pada lahan perkebunan kelapa di Minahasa Utara sebanyak 9 bangsa, 17 keluarga, 23 jenis dan kelimpahannya 1923 individu. Jenis burung yang memiliki kelimpahan tertinggi adalah Collocalia esculenta sebanyak 204 individu dengan kepadatan 5,10 individu/ha, kemudian disusul oleh jenis Cypsiurus balasiensis (198 individu, 4,95 individu/Ha) dan Corvus enca (196 individu,; 4,90 individu/Ha). Jenis burung dengan kelimpahan terdendah yaitu Centropus bengalensis sebanyak 8 individudengan kepadatan 0,20 individu/ha (Tabel 1). 
Alotia dkk., Biodiversitas Burung... $\mid 4$

Tabel 1. Indeks biodiversitas burung pada perkebunan kelapa di Kabupaten Minahasa Utara Provinsi Sulawesi Utara.

\begin{tabular}{clccccc}
\hline No & Jenis & $\mathrm{N}$ & $\mathrm{D}$ & $\mathrm{Pi}$ & $\mathrm{Ln} \mathrm{pi}$ & $\mathrm{Pi} \mathrm{Ln} \mathrm{pi}$ \\
\hline 1 & Penelopides exarhatus & 24 & 0.60 & 0.01 & -4.38 & -0.05 \\
2 & Accipiter nanus & 46 & 1.15 & 0.02 & -3.73 & -0.09 \\
3 & Anthreptes malacensis & 172 & 4.30 & 0.09 & -2.41 & -0.22 \\
4 & Ardea purpurea & 10 & 0.25 & 0.01 & -5.26 & -0.03 \\
5 & Bubulcus ibis & 113 & 2.83 & 0.06 & -2.83 & -0.17 \\
6 & Corvus enca & 196 & 4.90 & 0.10 & -2.28 & -0.23 \\
7 & Centropus bengalensis & 8 & 0.20 & 0.00 & -5.48 & -0.02 \\
8 & Cypsiurus balasiensis & 198 & 4.95 & 0.10 & -2.27 & -0.23 \\
9 & Coracina dohertyi & 26 & 0.65 & 0.01 & -4.30 & -0.06 \\
10 & Collocalia esculenta & 204 & 5.10 & 0.11 & -2.24 & -0.24 \\
11 & Cynittris jugularis & 189 & 4.73 & 0.10 & -2.32 & -0.23 \\
12 & Dicaeum celebicum & 41 & 1.03 & 0.02 & -3.85 & -0.08 \\
13 & Dicrurus densus & 100 & 2.50 & 0.05 & -2.96 & -0.15 \\
14 & Geopelia striata & 80 & 2.00 & 0.04 & -3.18 & -0.13 \\
15 & Gallirallus torquatus & 49 & 1.23 & 0.03 & -3.67 & -0.09 \\
16 & Halcyon chloris & 14 & 0.35 & 0.01 & -4.92 & -0.04 \\
17 & Halcyon diops & 15 & 0.38 & 0.01 & -4.85 & -0.04 \\
18 & Ixobrychus cinnamomeus & 12 & 0.30 & 0.01 & -5.08 & -0.03 \\
19 & Lonchura puntulata & 43 & 1.08 & 0.02 & -3.80 & -0.08 \\
20 & Pycnonutus aurigaster & 173 & 4.33 & 0.09 & -2.41 & -0.22 \\
21 & Phaenicophaeus calyorhynchus & 24 & 0.60 & 0.01 & -4.38 & -0.05 \\
22 & Scissirostrum dubium & 32 & 0.80 & 0.02 & -4.10 & -0.07 \\
23 & Zosterops atrifrons & 154 & 3.85 & 0.08 & -2.52 & -0.20 \\
\hline & Total & 1923 & 48.08 & 1.000 & -83.25 & -2.76 \\
\hline & Indek Keanekaragaman $\left(\mathrm{H}^{\prime}\right)$ & & & & & 2.76 \\
\hline
\end{tabular}

Jumlah jenis burung yang ditemukan pada semua lokasi penelitian sebanyak 23 jenis dengan indeks biodiversitas burung sebesar 2,76 termasuk dalam kategori sedang. Indeks biodiversitas burung dari tiga lokasi, disajikan pada Tabel 1.

Berdasarkan lokasi penelitian didapatkan bahwa Indeks biodiversitas tertinggi ditemukan pada lokasi 3 (desa Tatelu) dengan indeks Shannon Wiener $H^{\prime}=2,70$ dengan jumlah jenis sebesar 15 jenis. Lokasi 2 (Desa Maumbi) ditemukan sebanyak 19 jenis burung dengan indek biodiversitas sebesar 2,62. Sedangkan Lokasi 1 (Desa Pinili) memiliki nilai indeks biodiversitas lebih rendah yaitu sebesar 2,61, dengan jumlah jenis burung sebanyak 19 jenis.

Pada ketiga lokasi pengamatan indeks biodiversitas burung tidak berbeda nyata dikarenakan biodiversitas jenis pada ketiga lokasi pengamatan memiliki tipe habitat yang sama yaitu merupakan daerah perkebunan kelapa yang serupa hutan sekunder.

Menurut Deshmukh (1986) bahwa faktor yang membatasi tingginya biodiversitas jenis ialah kemampuan atau ketidakmampuan untuk menemukan sumber daya yang memadai. Tinggi atau rendahnya 
biodiversitas jenis pada masing-masing areal pengamatan disebabkan jenis makanan dan kondisi dari vegetasi yang berbeda pada tiap lokasi pengamatan serta selera makan tiap jenis burung berbeda-beda, sebagian jenis burung memakan bagian dari tumbuh-tumbuhan, seperti biji-bijian, nektar dan buah-buahan. Terdapat beberapa jenis burung yang memakan hewan lain, seperti serangga dan ikan.

Setiap jenis burung hanya memakan jenis makanan tertentu saja, maka ia akan hidup dengan nyaman pada daerah yang sesuai dengan dirinya tersebut (Ardly 1984). Semakin tinggi biodiversitas habitat akan mendukung tingginya biodiversitas jenis burung di wilayah tersebut, karena habitat bagi satwa liar secara umum berfungsi sebagai tempat untuk mencari makan, minum, istirahat, dan berkembang biak (Alikodra 1993).

\section{Status Jenis Burung Berdasarkan IUCN}

Status jenis burung yang ditemukan menurut International Union for Conservation of Nature (IUCN) didapatkan bahwa jumlah jenis burung yang diangap kurang Menghawatirkan LC (Least Concern) terdapat 21 jenis burung sedangkan status rentan VU (Vulnerable) terdapat satu jenis Penelopides exarhatus dan status hampir punah NT (Near Threatened) terdapat stau jenis Accipiter nanus (Tabel 2).

Tabel 2. Status burung yang ditemukan menurut IUCN

\begin{tabular}{|c|c|c|c|c|}
\hline Bangsa & Keluarga & Jenis & ICUN & keterangan \\
\hline \multirow{9}{*}{ Passeriformes } & Nectariniidae & $\begin{array}{l}\text { Cinnyris jugularis } \\
\text { Anthreptes malacensis }\end{array}$ & LC & $\begin{array}{c}\text { Kurang } \\
\text { mengkhawatirkan } \\
\text { Kurang } \\
\text { mengkhawatirkan }\end{array}$ \\
\hline & Zosteropidae & Zosterops atrifrons & LC & $\begin{array}{c}\text { Kurang } \\
\text { mengkhawatirkan }\end{array}$ \\
\hline & Dicruridae & Dicrurus densus & $\mathrm{LC}$ & $\begin{array}{c}\text { Kurang } \\
\text { mengkhawatirkan }\end{array}$ \\
\hline & Destrildidae & Lonchura prntulata & $\mathrm{LC}$ & $\begin{array}{c}\text { Kurang } \\
\text { mengkhawatirkan }\end{array}$ \\
\hline & Corvidae & Corvus enca & LC & $\begin{array}{c}\text { Kurang } \\
\text { mengkhawatirkan }\end{array}$ \\
\hline & Pycnonotidae & Pycnonutus aurigaster & LC & $\begin{array}{c}\text { Kurang } \\
\text { mengkhawatirkan }\end{array}$ \\
\hline & Dicaeidae & Dicaeum celebicum & $\mathrm{LC}$ & $\begin{array}{c}\text { Kurang } \\
\text { mengkhawatirkan }\end{array}$ \\
\hline & Sturnidae & Scissirostrum dubium & $\mathrm{LC}$ & $\begin{array}{c}\text { Kurang } \\
\text { mengkhawatirkan }\end{array}$ \\
\hline & Campephagidae & Coracina dohertyi & LC & $\begin{array}{c}\text { Kurang } \\
\text { mengkhawatirkan }\end{array}$ \\
\hline \multirow{3}{*}{ Cuculiformes } & Alcedinidae & $\begin{array}{l}\text { Halcyon chloris } \\
\text { Halcyon diops }\end{array}$ & LC & $\begin{array}{c}\text { Kurang } \\
\text { mengkhawatirkan } \\
\text { Kurang } \\
\text { mengkhawatirkan }\end{array}$ \\
\hline & Cuculidae & $\begin{array}{l}\text { Phaenicophaeus } \\
\text { calyorhynchus }\end{array}$ & LC & $\begin{array}{c}\text { Kurang } \\
\text { mengkhawatirkan }\end{array}$ \\
\hline & cuculade & Centropus bengalensis & LC & $\begin{array}{c}\text { Kurang } \\
\text { mengkhawatirkan }\end{array}$ \\
\hline \multirow[t]{2}{*}{ Apodiformes } & \multirow[t]{2}{*}{ Apodidae } & Collocalia esculenta & LC & $\begin{array}{c}\text { Kurang } \\
\text { mengkhawatirkan }\end{array}$ \\
\hline & & Cypsiurus balasiensi & LC & $\begin{array}{c}\text { Kurang } \\
\text { mengkhawatirkan }\end{array}$ \\
\hline \multirow{2}{*}{ Pelecaniformes } & & $\begin{array}{l}\text { Ixobryhus } \\
\text { cinnamomeus }\end{array}$ & LC & $\begin{array}{c}\text { Kurang } \\
\text { mengkhawatirkan }\end{array}$ \\
\hline & Ardeidae & Bubulcus ibis & LC & $\begin{array}{c}\text { Kurang } \\
\text { mengkhawatirkan }\end{array}$ \\
\hline Ciconiformes & & Ardea purpurea & $\mathrm{LC}$ & $\begin{array}{c}\text { Kurang } \\
\text { mengkhawatirkan }\end{array}$ \\
\hline Columbiformes & Collumbidae & Geopelia striata & LC & $\begin{array}{c}\text { Kurang } \\
\text { mengkhawatirkan }\end{array}$ \\
\hline Coraciiformes & Bucerotidae & Penelopides excrhatus & vU & Rentan \\
\hline Gruiformes & Ralidae & Gallirallus torquatus & LC & $\begin{array}{c}\text { Kurang } \\
\text { mengkhawatirkan }\end{array}$ \\
\hline
\end{tabular}




\section{Status Konservasi}

Kangkareng Sulawesi/julang Sulawesi merupakan jenis burung endemik Sulawesi yang berjuluk sebagai petani hutan kini jenis burung tersebut terancan punah akibat ulah manusia seperti perburuan liar dan penebangan hutan. Padahal, salah satu spesies burung rangkong di Indonesia itu berjasa besar dalam meregenerasi hutan. Berdasarkan keteranggan balai konservasi sumber daya alam (BKSDA) Sulawesi tengah. Populasi burung julang Sulawesi atau rangkong semakin berkurang meskipun masih dapat dilihat pada area tertentu. Jenis burung julang Sulawesi termasuk satwa yang dilindungi berdasarkan Undang-undang Nomor 5 Tahun 1990 tentang konservasi sumber daya alam dan ekosistemnya, juga PP Nomor 7 Tahun 1999 tentang pengawetan jenis tumbuhan dan satwa selain itu spesies ini juga terdaftar pada Lampiran II Konservasi perdagangan international tumbuhan dan satwa liar terancam punah (CITES).

Oleh karena itu butuh kesadaran dari masyarakat bahkan pemerintah setempat tentang pentingnya menjaga kelestarian alam bahkan kelestarian jenis burung kangkareng Sulawesi khususnya wilayah Kabupaten Minahasa Utara karena burung sangat berperan penting dalam meregenerasi hutan. Salah satu upaya dalam menjaga kelestarian dari jenis burung julang Sulawesi dan jenis burung lainnya yaitu dengan menjaga jenis burung ini diburu untuk dipelihara atau diburu untuk dijadikan sebagai bahan makanan, serta mengurangi kerusakan hutan akibat ahli guna lahan dan penebangan pohon secara besarbesaran tanpa memperhatikan kondisi lingkungan.

\section{KESIMPULAN}

Hasil penelitian menunjukkan bahwa indeks biodiversitas jenis burung pada perkebunan kelapa di Kabupaten Minahasa Utara Provinsi
Sulawesi Utara terdapat 9 bangsa, 17 keluarga, 23 jenis burung dan 1923 individu. Kelimpahan dan kepadatan jenis burung tertinggi ditemukan pada jenis Collocalia eculenta, sedangkan yang terendah burung jenis Centopus bengalensis. Indek keanekaragaman jenis burung yang ditemukan sebesar 2,761 dan termasuk dalam kategori sedang. Berdasarkan status IUCN didapatkan bahwa 21 jenis burung kurang menghawatirkan LC (least Concern), sedangkan status rentan VU (Vulnerable) terdapat 1 jenis Penelopides exarhatus dan status hampir punah NT (Near Threatened) terdapat 1 jenis Accipiter nanus

\section{DAFTAR PUSTAKA}

Alikodra HS (2002) Pengelolaan satwa liar, jilid 1 bogor: Fakultas Kehutanan, Institut Pertanian Bogor.

Alikodra HS (1993) Pengelolaan satwa liar jilid II. Institut Pertanian Bogor.

Andrew P (1992) The birds of Indonesia. Indonesian Ornithological Society, Jakarta.

Aratrakorn SS Thunhikorn, dan PF, Donald (2006) Changes in bird communities following conversion of lowland forest to oil palm and rubber plantations in southern Thailand. Bird Conservation International 16:71-82.

Ardly N (1984) Burung. PT. Widyatara. Jakarta.

Azman NM, Latip NSA, Sah, SAM, Akil MAMM, Shafie NJ, Khairuddin NL (2011) Avian diversity and feeding guilds in a secondary forest, an oil palm plantation and a paddy field in Riparian Areas of the Kerian River Basin, Perak, Malaysia. Tropical Life Sciences Research, 22(2), 45-64.

BPS Kabupaten Minahasa Utara (2008) Kabupaten Minahasa Utara dalam angka 2008. Airmadidi: BPS Kabupaten Minahasa Utara. 
7 | JURNAL BIOS LOGOS, FEBRUARI 2019, VOL. 9 NOMOR 1

Bibby CM, Jones S, Marsden (2000) Teknik-teknik Ekspedisi Lapangan: Survei Burung. Birdlife Internasional-Indonesia Programme, Bogor.

Coates BJ, Bishop KD (2000) Panduan Lapang Burung-Burung di Kawasan Wallacea: Sulawesi, Maluku, dan Nusa Tenggara.

Deshmukh I (1986) Ecology and Tropical Biology. Blackwell Scientific, Oxford.Diterjemahkan oleh Kartikawinata, K., dan Sarkat D. 1991. Ekologi dan Biologi Tropika. Yayasan Obor Indonesia. Jakarta.
Michael P (1995) Metode Ekologi Untuk Penyelidikan Ladang dan Laboratorium. UI-Press, Jakarta.

Sukmantoro W, Irham M, Novarino W., Hasudungan F, Kemp N., \& Muchtar M (2007) Daftar burung Indonesia. Bogor: Indonesian Ornithologists' Union.

Syafrudin D (2011) Keanekaragaman jenis burung pada beberapa tipe habitat di Tambling Wildlife Nature Conservation (TWNC) di Taman Nasional Bukit. 